\title{
Proposed computerized protocol for epidemiological study of patients undergoing microsurgery of the larynx
}

\author{
Guilherme Simas do Amaral Catani', Bettina Carvalho', Jorge Massaaki Ido Filho', Evaldo Dacheux de Macedo Filho', \\ José Simão de Paula Pinto ${ }^{3}$, Osvaldo Malafaia4, Henrique Jorge Stahlke Jr.5. \\ 1) M.D., ENT by ABORL. Physician from the ENT Department of HC/UFPR. \\ 2) M.D. by UFPR. Resident from the ENT Department of HC/UFPR. \\ 3) $\mathrm{PhD}$. in Informatics applied to the teaching and research in Surgery - medicine (2005). Professor of the Science and Information management department of UFPR. \\ 4) $\mathrm{PhD}$ in Medical Anatomy (1976). Professor of the postgraduation programe in Surgery principles of Faculdade Evangelica do Parana. \\ 5) $\mathrm{PhD}$ in the Surgical Clinics of the postgraduation programe at UFPR (2002). Professor and Coordinator of the Vascular Surgery discipline of HC/UFPR. \\ Institution: Hospital IPO (Instituto Paranaense de Otorrinolaringologia). \\ Curitiba / PR - Brazil. \\ Endereço para correspondênica: Bettina Carvalho - Rua Clovis Bevilaqua, 180 - Bairro Cabral - Curitiba / PR - Brazil - Zip code: $80035-080$ - E-mail: \\ bettinacarvalho@yahoo.com.br \\ Article received in December 6, 2011. Article approved in March 18, 2012
}

\section{SUMMARY}

Introduction: The merging of medicine with information technology facilitates the retrieval of stored data, aiding the conduct of research with greater scientific rigor. Studies in the field of otorhinolaryngology, specifically in the area of laryngology and voice, are of fundamental importance, since $70 \%$ of the economically active need their voice to work.

Objective: To create a computerized protocol of the diseases of the larynx, apply and validate it, and use it to evaluate patients undergoing laryngoscopic microsurgery of the larynx.

Method: We created a database of ENT diseases through a literature review of textbooks and scientific articles. Next, we computerized the data and incorporated it into the $\mathrm{SINPE}^{\odot}$, creating a master protocol (ENT diseases) and a specific protocol (laryngeal diseases). Data were collected prospectively from patients undergoing laryngeal microsurgery in the ENT Hospital of Paraná. The collected data were analyzed with graphs through the SINPE ${ }^{\odot}$ Analyzer module.

Results: We evaluated 245 patients aged 9-79 years, and determined that 36.61\% (93 patients) underwent surgery for the presence of polyps on the vocal folds, 12.6\% (32) underwent surgery for papillomatosis, and 11.83\% (29) underwent surgery for intracordal cysts.

Conclusions: The creation of an electronic database of clinical ENT diseases was feasible. We were also able to implement and validate the protocol. The database may be released to physicians involved in clinical data collection and retrieval of information to conduct scientific research in an organized manner. The most common laryngeal disorders identified were polyps, papilloma, and intracordal cysts.

Keywords: larynx, microsurgery, epidemiologic studies.

\section{INTRODUCTION}

Lesions that affect the vocal tract, especially the vocal folds, are common and produce symptoms mostly characterized by dysphonia. Thus, these lesions have a negative influence on the personal and professional relationships of the individual. Although they are benign, many of these lesions require medical treatment $(1,2)$.

Currently, data processing and computers play a central role in the production and dissemination of knowledge, especially scientific information. Computerized databases and electronic protocols facilitate the organization and recovery of data and increase the willingness of volunteers to participate in high-quality research that is essential for the prevention, early diagnosis, and treatment of various diseases (3-18), including laryngeal lesions.
The objectives:

1. Create a computerized protocol of diseases of the larynx.

2. Apply and validate a protocol for data collection.

3. Evaluate changes in patients undergoing laryngoscopic microsurgery of the larynx.

\section{MeTHOD}

This was a prospective study conducted using a computerized protocol in patients undergoing laryngeal microsurgery from February 2010 to February 2011 at the Hospital Paranaense de Otorrinolaringologia (Hospital IPO).

This study was approved by the hospital's ethics committee for research on human beings. 


\section{Benign lesions of the larynx}

Benign lesions of the larynx include nodules, epidermoid cysts, retention cysts, vocal sulcus, polyps, Reinke's edema, vascular dysgenesis, micromembranes, granulomas, and papillomas. Although the initial causes and treatments for these benign lesions differ, surgery, when necessary, follows the same general procedures.

The surgical procedure aims to improve glottic closure and eliminate the factors that interfere with the normal vibration of vocal folds $(1,2)$.

\section{Criteria for inclusion}

This study included patients who were diagnosed with laryngeal diseases with surgical indication and underwent laryngeal microsurgery at the Hospital IPO from February 2010 to February 2011. We included patients of both sexes and did not set age limits for inclusion.

\section{Criteria for exclusion}

Patients who did not fit the criteria for inclusion and/ or did not participate in the study.

\section{$\mathrm{SINPE}^{\odot}$ electronic protocol}

The $\operatorname{SINPE}^{\bullet}$ (integrated electronic protocol) and a protocol-based computer program capable of storing and manipulating data on a theoretical basis were used. This protocol was incorporated into a line of research called "electronic computer protocols," which was implemented by the Program of Postgraduate Studies in Clinical Surgery, Department of Health Sciences, of the Federal University of Parana (Universidade Federal do Parana/UFPR), in the late 1990s. Its main objective was the development of a database that enables researchers to collect and store information and allows quick and secure access to scientific data $(19,20)$.

The proposal for creating an electronic form and completing protocols is well founded, and several areas of the health sciences (medicine, surgery areas of the digestive tract, urology, ophthalmology, nursing and management) have already developed protocols and incorporated them into the electronic SINPE ${ }^{\odot}$. Protocols are under development for other areas such as bariatric surgery, orthopedics, anesthesiology, and nutrition $(21,22)$.

\section{Creation of the protocol}

For this study, we created a protocol that included all the specific electronic clinical data (history-taking and physical examination data); data from laboratory tests, operations performed, and follow-up examinations; and prospectively collected data.

A theoretical basis for generic data specific to otolaryngology (ENT) and laryngology was created on the basis of the textbook "Brazilian Treaty of Otolaryngology" and "Cummings Otolaryngology - Head and Neck Surgery" and a review of literature from the last 30 years.

The following 2 protocols were created through this database: the master protocol (general ENT) and the specific protocol (laryngology).

Clinical data from papers were recorded on a computer. Once the collection was stored, the computerized protocol employed through the SINPE ${ }^{\odot}$ Analyzer module of the program was used to generate reports, graphs, and statistics summarizing the main findings.

\section{RESULTS}

We evaluated 245 patients, aged 9-79 years, who had laryngeal diseases with indication for microsurgery from February 2010 to February 2011. The patient set included 139 women (56.73\%) and 106 men (43.27\%). The most prevalent age groups were 23 to 37 years ( 93 , $37.96 \%)$ and 37 to 51 years $(77,31.43 \%)$.

These results are shown in Graphs 1, 2, and 3.

Epinephrine infusion was not used in any of the cases for polyps treatment $(n=93)$. The technique of holding the polyp and performing resection with microscissors was used for most of the cases $(79 ; 84.95 \%)$. In the remaining 14 cases (15.05\%), we used the technique of micro and medial flap section with micro-scissors.

In the treatment of laryngeal papillomatosis, all patients $(n=32)$ underwent excision with a cooling agent, and cidofovir treatment was used in 31 (96.88\%) patients.

For epidermoid cysts, the treatments included creating a micro side flap in 14 cases (48.28\%), an intermediate micro flap in 13 cases (44.83\%), and enucleation of the cyst in 2 cases (6.9\%).

All patients with vocal nodules $(n=25)$ underwent phonomicrosurgery for treatment.

In Reinke's edema ( $n=24)$, the most widely used technique was fabrication of a micro medial flap, aspiration, 


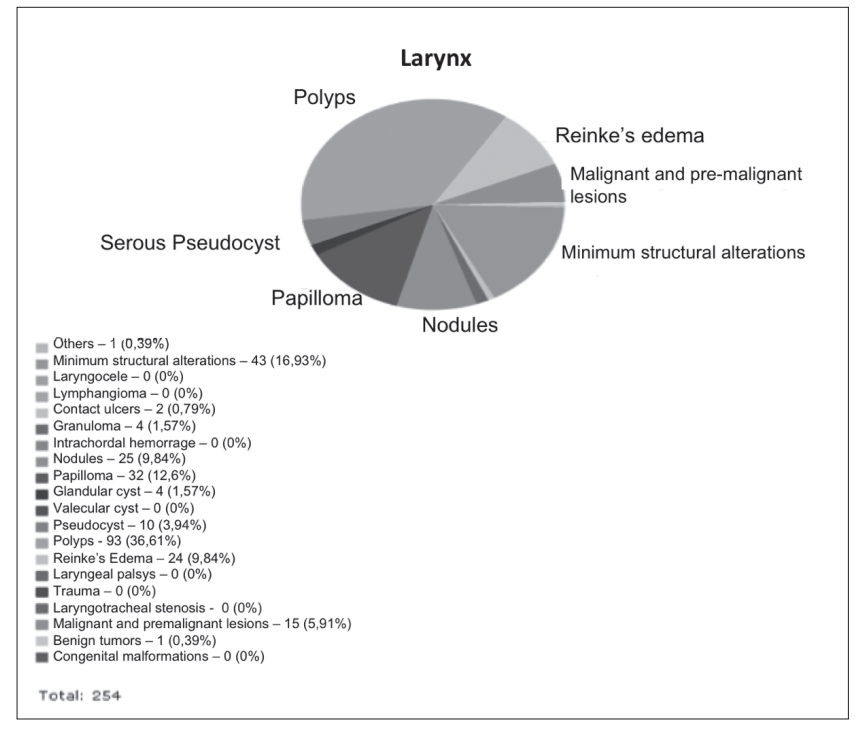

Graphs 1. Results of laryngeal lesions.

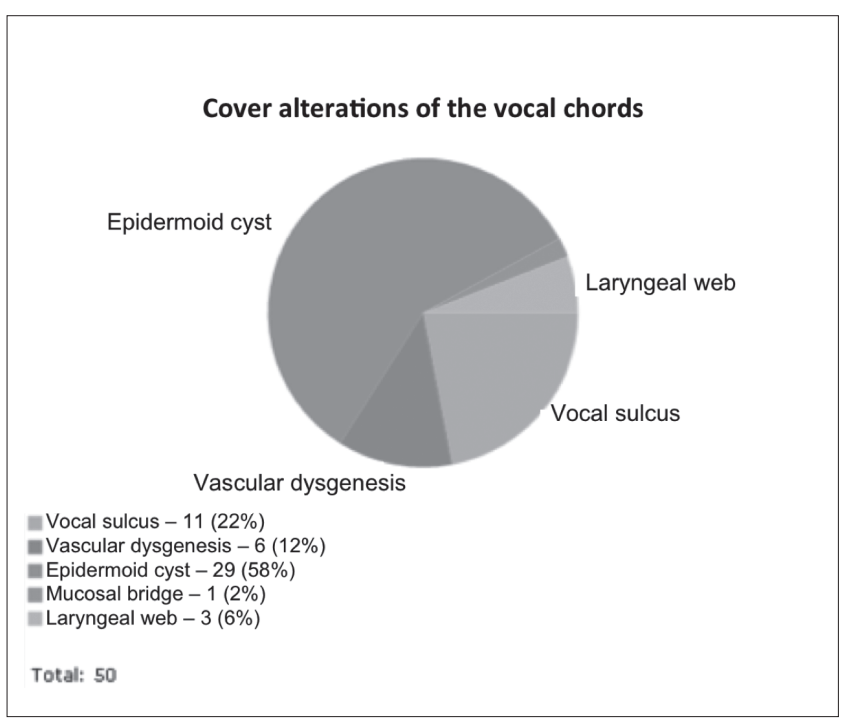

Graphs 2. Results of cover alterations.

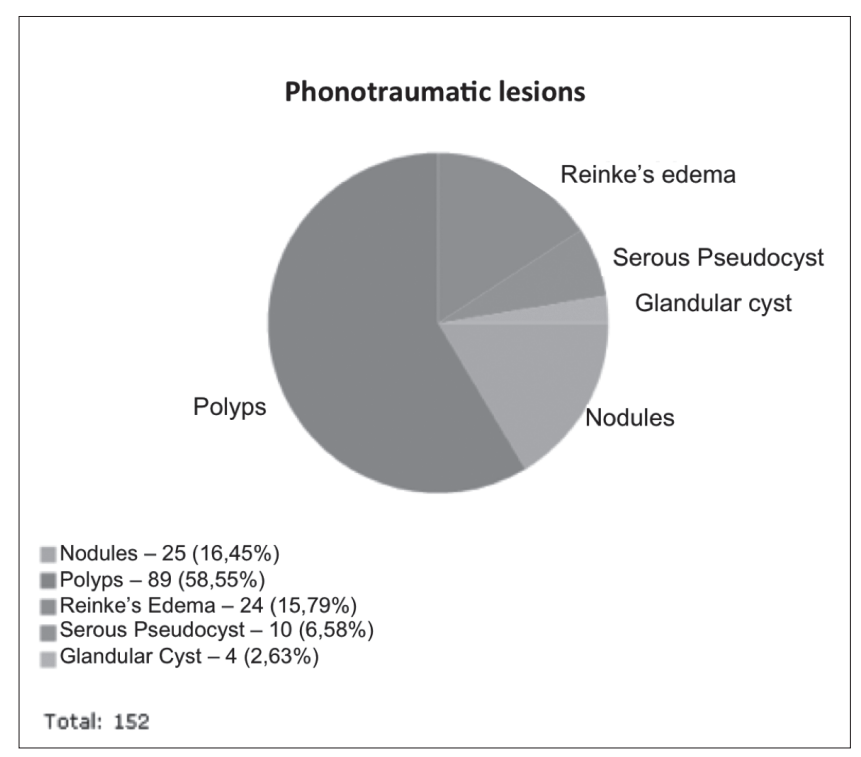

Graphs 3. Results of phonotraumatic lesions. and excision of redundant mucosa (14 cases, 58.33\%), followed by intermediate micro-flap fabrication, aspiration, and excision of redundant mucosa ( 7 cases, $29.17 \%$ ). The following procedures were performed in 1 case each (4.17\%): medial micro-flap and aspiration, intermediate micro-flap and aspiration, and lateral micro-flap, aspiration, and excision.

Treatment of the sulcus was performed by internal sectioning of the vocal ligament in 10 cases (71.43\%) and by detachment in 4 patients (28.57\%).

\section{DISCUSSION}

The incidence of each benign vocal fold has been rarely described in recent Brazilian literature; therefore, clinicians and researchers must rely on foreign or old literature.

An epidemiological study of laryngeal diseases requiring surgical treatment can help clinicians plan preventive and curative measures and facilitate training of doctors who are qualified to treat patients with laryngeal diseases that have a high incidence.

The series of cases involving laryngeal microsurgery discussed herein are summarized in Table 1.

In contrast to the reports obtained by LeHMANN (25) and KLEINSASSER (31), in which laryngeal microsurgery was conducted mainly in men, women accounted for $56.73 \%$ of the patients in this study. This proportion of female patients is similar to that in the study by DAILEY (27), which reported that $62 \%$ of surgical patients were women, and the findings obtained by Perazzo et al. (34)

The age group that corresponds to the economically active population (23-51 years) represented almost $70 \%$ of the patients who underwent surgeries in our study, signifying the major economic and social impact of these diseases. These findings are similar to those obtained in the studies by PERAzzo (34), Lehmann (25), and Kleinsasser (31), justifying the intensification of campaigns for disease prevention and guidance for vocal diseases. Additionally, this justifies actions against smoking since smoking is a causal or aggravating factor for most of these diseases.

Inflammatory and infectious diseases accounted for more than 80\% of the cases (198 cases). Among these diseases, speech-trauma injuries accounted for more than half of the cases. Polyps, nodules, and Reinke's edema accounted for 142 cases (55.9\%). These findings, which were similar in all series surveyed, call attention to the 
Table I.

\begin{tabular}{|c|c|c|c|c|c|c|c|c|c|c|c|c|}
\hline Author|Disease & $\mathrm{POL}$ & PAP & NOD & ER & PS & $\mathrm{Cl}$ & GR & S V & MD & VD & LP & CA \\
\hline Catani, Macedo, and Ido & $36.61 \%$ & $12.60 \%$ & $9.84 \%$ & $9.45 \%$ & $4.08 \%$ & $11.83 \%$ & $1.57 \%$ & $4.50 \%$ & $1,25 \%$ & $2.45 \%$ & $1.63 \%$ & $4.50 \%$ \\
\hline Kumar (23) & $56.00 \%$ & & $12.00 \%$ & $6.66 \%$ & & $14.66 \%$ & $6.66 \%$ & & & & $4.00 \%$ & \\
\hline Abrol (24) & & $6.00 \%$ & & & & $3.50 \%$ & & & & & & \\
\hline Lehmann (25) & $24.90 \%$ & $4.00 \%$ & $4.90 \%$ & $16.50 \%$ & & $6.30 \%$ & $4.10 \%$ & $5.60 \%$ & & & $6.60 \%$ & $13.70 \%$ \\
\hline Bastic & $25.80 \%$ & & $67.74 \%$ & & & | $1.29 \%$ & & $6.45 \%$ & & $3.22 \%$ & & \\
\hline Dailey (27) & $36.00 \%$ & & $39.00 \%$ & $12.00 \%$ & & & $2.00 \%$ & & & & & \\
\hline Bouchayer (28) & | $1.00 \%$ & $<1 \%$ & $24.00 \%$ & $6.00 \%$ & $6.00 \%$ & $17.00 \%$ & $1.00 \%$ & $12.00 \%$ & $3,00 \%$ & & & \\
\hline Mossallam (29) & $42.00 \%$ & & $9.00 \%$ & $14.00 \%$ & & $18.00 \%$ & $7.00 \%$ & & & & $4.00 \%$ & \\
\hline Herrington-hall (30) & $11.40 \%$ & & $21.00 \%$ & $14.00 \%$ & & $1.00 \%$ & $1.00 \%$ & & & & $4.10 \%$ & $9.70 \%$ \\
\hline Kleinsasser (3I) & $18.96 \%$ & $5.28 \%$ & $2.76 \%$ & $10.00 \%$ & & $5.52 \%$ & $2.32 \%$ & & & $0.28 \%$ & & \\
\hline Haas (32) & $20.77 \%$ & $0.70 \%$ & $2.95 \%$ & $10.14 \%$ & & $4.92 \%$ & $0.98 \%$ & & & & & $18.00 \%$ \\
\hline Perazzo (34) & $25.00 \%$ & $7.50 \%$ & $12.50 \%$ & $7.50 \%$ & & $40.00 \%$ & $2.50 \%$ & $7.50 \%$ & & & & \\
\hline
\end{tabular}

Abbreviations: $\mathrm{POL}=$ Polyp, $\mathrm{PAP}=$ Papilloma, $\mathrm{NOD}=$ Nodules, $\mathrm{ER}=$ Reinke's Edema, $\mathrm{PS}=\mathrm{Pseudocyst}$, CI $=\mathrm{Cyst}$, $\mathrm{GR}=$ Granuloma, $\mathrm{SV}=$ Sulcus, $\mathrm{MD}=$ Micro-diaphragm, $\mathrm{VD}=$ Vasculo-dysgenesis, $\mathrm{LP}=$ Leukoplakia, and CA $=\mathrm{Carcinoma}$

results of BASTIAN (26), where more than $90 \%$ of the injuries involved speech trauma.

The lesions that appeared most frequently in the series described for comparison were polyps, nodules, Reinke's edema, and cysts and granulomas.

The most common injury in this study was vocal polyps, which was found in 93 patients (36.61\%) (Figure 1 ). These results are consistent with those in the reports by Haas (32), Mossallam (29), Lehmann (25), and Kleinsasser (31), in which the polyp was the main indication for microsurgery of the larynx. KumAr et al. (23) evaluated a series of 75 lesions during surgery and found the highest incidence of polyps in the comparison series: $56 \%$. These numbers are in contrast with the findings obtained by ABROL (24), who reported that polyps were found in less than $1 \%$ of patients.

In this study, surgery was performed in all patients using a cold dissection technique. This technique provides excellent results with less tissue damage and less risk than that involved in surgeries using laser. Adrenaline infusion, as suggested by Hochman (34), was not used.

The decision to use the micro flap with microscissors or simply hold the polyp section with microscissors was based on the presentation of the polypoid lesion. Pedunculated polyps, which were present in 79 cases, were treated surgically by gripping the lesion section with micro-scissors. The 14 cases with sessile polyps were treated by micro-flap resection with microscissors.

Papilloma, which was the second most prevalent disease, was found in 32 patients (12.6\%) (Figure 1). ABroL (24) reported the presence of papilloma in 12 of 200 patients $(6 \%)$ that underwent surgery. In a statistical analysis of 2,500 procedures in 2,090 patients, KLEINSASSER (31) reported microlaryngoscopy papillomatosis in 132 patients $(5.28 \%)$. This was in contrast to the findings obtained by Bouchayer et al. (28) and HaAs (32), who reported papilloma in less than $1 \%$ of surgical patients. The incidence of papilloma operations in our series was the highest among all others surveyed, which is presumably because patients are referred to the Hospital of the Paraná Institute of Otorhinolaryngology (Hospital IPO) for the treatment of laryngeal papillomatosis.

Papilloma patients in this study were treated with the cold surgical technique because recurrence and sequential surgeries are characteristic of this disease. This technique causes less tissue damage and yields better voice quality than the laser technique. Several adjuvant therapies have been advocated for papillomatosis. Currently, the most promising agent seems to be the antiviral cidofovir, which is injected into the bed from which the lesion was removed. This treatment was used in 31 of 32 patients; the 1 patient who did not receive this treatment could not afford to buy the drug.

Vocal cysts were the third most common form of injury, occurring in 29 patients (11.83\%) (Figure 2). The incidence of this cyst was $18 \%$ in the study by Mossallam et al. (29) (the highest incidence) and 17\% in the study by Bouchayer et al. (28) In contrast, the incidences were $5.52 \%$ and $3.5 \%$ in reports by KLeINSASSER (31) and ABrol (24), respectively. This wide variation in findings reflects the difficulties in diagnosing this disease. The diagnosis of epidermoid cyst is often confused with vocal nodules, both of which are generally located in the middle third of the vocal fold.

In this series, 3 technical treatment variations were used based on the location and depth of the cysts. Simple incision and enucleation of the cyst was used in cases of 
extremely superficial cysts, which occurred in 2 patients (6.9\%). Cysts that were deeper and closer to the vocal ligament, which were found in 14 patients ( $48.28 \%$ ), were treated with the micro-flap side technique. Cysts closer to the free edge of the vocal folds occurred in 14 patients (44.83\%) and were treated with the micro-flap side technique. These results are similar to those of Johns (35) and Merati. (36)

Vocal nodules, which had the fourth-highest incidence (Figure 1), were found in 25 patients (9.84\%). This finding was similar to those obtained by Mossallam et al. (29), who noted these nodules in 9\% of the cases in a series of 106 lesions. BOUCHAYER et al. (28) found these nodules in $24 \%$ of the cases in a series of 1283 patients, which is more than double our findings. It is noteworthy that most patients with vocal nodules are treated with speech therapy, and surgery is indicated for cases that do not evolve properly with this treatment.

The technique used in 25 patients involved the use of the BOUCHAYer gripping clamp and section of the nodules, with care taken to exclude the lamina propria. This technique allows the excision of the nodule surface without damage to the vocal ligament. All patients were referred for speech therapy after surgery.

Reinke's edema was the fifth most frequent disease in our study, occurring in 24 patients (9.45\%) (Figure 3). These results are similar to those described by KLEINSASSER (10\%) (31) and Hass (10.14\%) (32). LehmanN (25) reported the highest incidence (16.5\%), whereas BOUCHAYER et al. (28) reported an incidence of $6 \%$.

The range of techniques used in this series was based on the degree of Reinke's edema and the location of the polypoid gelatinous tissue. A medial, lateral or intermediate micro flap was fabricated for the opening of the Reinke space, releasing the yellow and thick gelatinous liquid, which was aspirated. Afterwards, the rough edges of the mucosal flaps were put together. Resection was performed using forceps and micro Bouchayer scissors in cases of redundant mucosa.

A sulcus was found in 11 patients (4.5\%) (Figure 2), which was lower than the incidence reported by BOUCHAYER et al. (12\%). (28) The results of this study were close to those obtained by Lehmann (5.60\%) (25) and Bastian (6.45\%) (26). The identification of this lesion, as well as the vocal cyst, largely depends on the evaluator's knowledge of its existence and its main features.

Various microsurgical techniques have been proposed in the literature in order to alleviate the defect caused by the chordal groove in the structure and, consequently, to improve the voice quality. The most frequently used techniques include the internal section of the vocal ligament and techniques employing microsutures, collagen fillers, fat, Teflon, apatite hydroxide, Gore-Tex $^{\circledR}$, and muscular fascia implants. Presently, a consensus regarding the best surgical method does not exist, and the results and complication rates of these techniques vary considerably. In this study, the technique of incision and detachment of the groove was indicated for 4 patients with a stria minor sulcus. In cases of greater stria sulcus (10 patients), we used the internal section vocal ligament (SILV) technique developed by MACEDO et al. This technique consists of an upper cordotomy, medial displacement of the groove at the free edge of the mucosa, lateral displacement of the muscle layer, exposure of the vocal ligament, transverse ligament sections, placement of autografts, and closure plans. (37)

Carcinoma was found in 11 patients (4.5\%) (Figure 1). Herrington-Hall et al. (30) conducted a retrospective study of 1262 patients and found carcinoma in $9.7 \%$ of these cases. HaAs (32) published the findings of 1420 patients and reported carcinoma in 18\% of cases, which is much higher than the results of this study because it is a reference center for laryngeal cancer.

Exophytic early carcinomas often have a typical granulomatous appearance, which raises a strong suspicion of malignancy during clinical examination and endoscopy. However, these carcinomas can mimic benign lesions such as papillomas or polyps. (38) Microscopic evaluation of biopsies is the only safe way to dispose of premalignant and malignant tumors and is the only method for establishing a correct diagnosis. Stroboscopy can be very helpful for distinguishing between precancerous and cancerous lesions because the vocal fold vibration is decreased in invasive lesions. $(39,40)$

\section{CONCLUSION}

The software $\operatorname{SINPE}^{\circ}$ is a suitable tool for clinical research and has contributed to and facilitated prospective survey data collection. The creation of an electronic database of clinical ENT diseases and the implementation and validation of the protocol are feasible. This database can be released to physicians involved in clinical data collection, and the retrieval of information will help them conduct scientific research in an organized manner.

The most common injuries in this series were the vocal polyp, present in 93 patients (36.61\%), followed by papilloma (12.6\%) and intracordal cyst (11.83\%). 


\section{REFERENCES}

1. Sociedade Brasileira de Otorrinolaringologia. Tratado de Otorinolaringologia. São Paulo: Roca, 2003.

2. Flint PW, Haughey B H, Lund V J, Niparko J K. Cummings Otolaryngology - Head and Neck Surgery. 5 th ed. New York: Elsevier Health Sciences, 2010.

3. Barnett G O. The application of computer-based medicalrecord systems in ambulatory practice. The New England journal of medicine, 1984; 310(25):1643-1650.

4. Bemmel J, Van Musen M. Handbook of Medical Informatics. New York: Springer-Verlag, 1997.

5. Bleich HL. Enemy radar, theoretical physics, and computer-assisted diagnosis. M.D. computing/:computers in medical practice, 1991; 8(5):269-270.

6. Blois MS, Shortliffe EH. The computer meets medicine: emergence of a discipline. In: Shortliffe EH, Perreault LE (Eds.); Medical informatics: computer applications in health care. p.3-36, 1990. New York: Addison-Wesley Publishing.

7. Coiera E. Guide to medical informatics, the internet and telemedicine. London: Chapman \& Hall Medical, 1997.

8. Duffy J. Utilizing computers in evaluating health data. Bull N Y Acad Med, 1970; 46(11):952-963.

9. Francais A, Vesin A, TimsitJF. Como realizar ensaios clínicos em terapia intensiva utilizando base de dados de alta qualidade. Rev Bras Ter Intensiva, 2008; 20(3):296-304.

10. Hersh W, Hickam D. Use of a multi-application computer workstation in a clinical setting. Bulletin of the Medical Library Association, 1994; 82(4):382-389.

11. Kohane IS. Exploring the functions of World Wide Webbased electronic medical record systems. M.D. computing/ : computers in medical practice, 1996; 13(4):339-346.

12. Mcdonald T, Blignaut PJ. A comparison of a manual and a computer system in a primary health care clinic. Curationis, 1998; 21(3):8-13.

13. Mira E, Lanza L, Castelli A, Benazzo M, Tinelli C. A computerized database for managing otorhinolaryngologic oncology patients. Acta otorhinolaryngologica Italica/ : organo ufficiale della Società italiana di otorinolaringologia e chirurgia cervico-facciale, 1998; 18(3):155-63.

14. Nelson EC, Splaine ME, Batalden PB, Plume SK. Building measurement and data collection into medical practice. Annals of Internal Medicine, 1998; 128(6):460-466.

15. Pryor DB, Califf RM, Harrell FE, et al. Clinical databases. Accomplishments and unrealized potential. Medical Care, 1985; 23(5):623-647.

16. Stetson D. Andrew W. The CPR: getting physicians on board. Healthcare informatics/: the business magazine for information and communication systems, 1996; 13(6):20,22,24.

17. Watts MS. Automated and programmed services in health care. Calif Med, 1971; 114(4):54-55.

18. Wechsler R, Anção MS, Campos CJRD, Sigulem D. A informática no consultório médico. J Pediatr (Rio J), 2003; 79(Supl 1):3-12.

19. Malafaia O, Borsato EP, Pinto J. Gerenciamento do conhecimento em protocolos eletrônicos e coleta de dados. 2003. Curitiba: Simpósio Internacional de Gestão do Conhecimento, 3 .

20. Borsato EP, Pinto JSP, Malafaia O. Um repositório de metadados para protocolos de pesquisa na área médica. In: CBIS'2004-IXCongresso Brasileiro de Informática em Saúde, 2004, Ribeirão Preto. Anais Online. SBIS, 2004.

21. Pinto JSP. Interface da visibilização de informações para o sistema integrado de protocolos eletrônicos. Tese (Doutorado) - Setor de Ciências da Saúde, Universidade Federal do Paraná, Curitiba, 2005.

22. Sigwalt MF. Base eletrônica de dados clínicos das doenças do esôfago. Dissertação (Mestrado). Setor de Ciências da Saúde, Universidade Federal do Paraná, Curitiba, 2001.

23. Kumar P, Murthy S, Kumar R. Phonomicrosurgery for benign vocal fold lesions. Indian Journal of Otolaryngology and Head and Neck Surgery, 1970; 55(3):184-186.

24. Abrol BM, Natarajan PR. Endolaryngeal microsurgery. Indian Journal of Otolaryngology and Head \& Neck Surgery, 1976; 28(3):126-128.

25. Lehmann W, PampurikJ, GuyotJP. Laryngeal pathologies observed in microlaryngoscopy. ORL; journal for oto-rhinolaryngology and its related specialties, 1989; 51(4):206-215.

26. Bastian RW. Vocal fold microsurgery in singers. Journal of voice/ : official journal of the Voice Foundation, 1996; 10(4):389-404.

27. Dailey SH, Spanou K, Zeitels SM. The evaluation of 
benign glottic lesions: rigid telescopic stroboscopy versus suspension microlaryngoscopy. Journal of voice/ : official journal of the Voice Foundation, 2007; 21(1):112-118.

28. Bouchayer M, Cornut G. Microsurgery for benign lesions of the vocal folds. Ear, nose, \& throat journal, 1988; 67(6):446-449, 452-454, 456-464 passim.

29. Mossallam I, Kotby MN, Ghaly AFEA. Histopathological aspects of benign vocal fold lesionsassociated with dysphonia. In: KirchnerJA (Ed.); Vocal Fold histipathology: A symposium. San Diego: College-Hill, 1986, p.65-80.

30. Herrington-Hall BL, Lee L, Stemple JC, Niemi KR, Mchone MM. Description of laryngeal pathologies by age, sex, and occupation in a treatment-seeking sample. The Journal of speech and hearing disorders, 1988; 53(1):57-64.

31. Kleinsasser O. Microlaryngoscopy and endolaryngeal microsurgery. II: A review of 2500 cases. HNO, 1974; 22(3):69-83

32. Haas E, Döderlein K. Endolaryngeal microsurgery. A report of our experiences in the years from 1966 to 1976. Laryngologie, Rhinologie, Otologie, 1978; 57(3):235-42.

33. Perazzo PSL, Cota AC, Moura MPC, Almeida WLC. Pré e pós-operatório em pacientes submetidos a microcirurgias das principais lesões benignas da laringe. Braz J Otorhinolaryngol, 2000; 66(5):507-510.

34. Hochman II, Zeitels SM. Phonomicrosurgical management of vocal fold polyps: the subepithelial microflap resection technique. Journal of voice/ : official journal of the Voice Foundation, 2000; 14(1):112-118.

35. Johns MM. Update on the etiology, diagnosis, and treatment of vocal fold nodules, polyps, and cysts. Current opinion in otolaryngology \& head and neck surgery, 2003; 11(6):456-461.

36. Merati A, Andrews R, Courey M, Garrett C, Ossoff R. Phonomicrosurgical management of intracordal cysts. Operative Techniques in Otolaryngology-Head and Neck Surgery, 1998; 9(4):230-237.

37. Macedo Filho ED, Caldart AU, Assis C. etal. Secção Interna do Ligamento Vocal - Nova Técnica para Tratamento do Sulco Vocal. Arq. Int. Otorrinolaringol, 2007; 11(3):254-259.

38. Poels PJP, Jong FICRS de, Schutte HK. Consistency of the preoperative and intraoperative diagnosis of benign vocal fold lesions. Journal of Voice, 2003; 17(3):425-433.

39. Sadri M, Mcmahon J, Parker A. Management of laryngeal dysplasia: a review. European archives of oto-rhinolaryngology/ : official journal of the European Federation of Oto-Rhino-Laryngological Societies (EUFOS) / : affiliated with the German Society for Oto-Rhino-Laryngology - Head and Neck Surgery, 2006; 263(9):843-52.

40. Schultz P. Vocal fold cancer. European annals of otorhinolaryngology, head and neck diseases, 2011. http:/ /www.ncbi.nlm.nih.gov/pubmed/21959270. Acesso em: 1/ $11 / 2011$. 